\title{
A crossed Kana agraphia
}

\author{
K. Abe ${ }^{1}$, R. Yokoyama ${ }^{2}$ and T. Yanagihara ${ }^{1}$ \\ 'Department of Neurology, Osaka University Medical School, and ${ }^{2}$ Division of Speech \\ Therapy, Kishiwada Tokushukai Hospital, Osaka, Japan \\ Correspondence to: K. Abe, Department of Neurology, Osaka University Hospital, 2-2 \\ Yamadaoka, Suita, Osaka 565, Japan
}

\begin{abstract}
We report a right-handed man who developed selective Kana (phonogram) agraphia following an infarct in the non-dominant right cerebral hemisphere. His ability for comprehension, reading and writing of Kanji (ideogram) was unaffected. Kana errors consisted of substitution with another letter and the number of target words was well preserved. The lesion responsible for his Kana agraphia included the right Wernicke's area (the posterior one-third or one-half of the superior temporal gyrus) on MRI, but he did not have aphasia. Based on these findings, we conclude that the language function in some dextral people may be partially lateralized to the right cerebral hemisphere.
\end{abstract}

Keywords: Crossed agraphia - Graphic center - Kana - Language lateralization

\section{INTRODUCTION}

It is well known that crossed aphasia may occur after a single non-dominant cerebral hemispheric lesion, and it is estimated to be present in $0.4-3.5 \%$ of dextral patients with right hemispheric lesions (Leischner, 1969; Tanaka et al., 1987; Sakurai et al., 1992; Roeltgen, 1993). The Japanese script system consists of two different types of letters: Kanji is ideogram taken from Chinese and Kana is phonogram having a syllable in Japanese. The processing of Kanji and Kana is considered to depend on different neural systems, and agraphia of Kana or Kanji may develop independently (Leischner, 1969; Sato et al., 1983; Kimura et al., 1986; Tanaka et al., 1987; Sakurai et al., 1992; Roeltgen, 1993). However, crossed Kana agraphia following non-dominant hemispheric lesion has not been reported. We report a selective Kana agraphia with preserved Kanji writing following a lesion in the non-dominant right hemisphere in a right-handed man.

\section{CASE REPORT}

The patient was a 60 year old right-handed retired banker. There was no history of neurological illness or developmental learning disorder in childhood. He had no difficulty in linguistic skills during his student age and thereafter he enjoyed good health until he suddenly experienced severe dizziness and was admitted to a hospital in December 1992. On examination, he had normal cranial nerve function, muscle strength, coordinated movement and sensory function. A computed tomographic (CT) scan demonstrated reduced attenuation in the right superior temporal gyrus, marginal gyrus and adjacent subcortex. He was referred to our hospital for further evaluation. On neurological examination he had normal cranial nerve function, muscle strength, muscle tone, coordinated movement and sensory function. He had normal cognitive function except for an impaired ability to write. A magnetic resonance image (MRI) demonstrated an abnormal signal in the right superior temporal gyrus, marginal gyrus and adjacent subcortex (Fig. 1).

$\mathrm{He}$ was attentive, cooperative and fully oriented to time and place. Digit span was 7 forward and 5 backward. The patient had always been fully right handed. All activities of the Edinburgh Handedness Inventory were carried out with the right hand (Oldfield, 1971). He scored 29 on the Mini-Mental State Examination (MMSE), the full score being 30. The error was in writing. We further evaluated his linguistic skills using a standard language test of aphasia (SLTA), i.e. a standardized aphasia test used in Japan (Takeda, 1977). On the SLTA, his ability for verbal comprehension $(35 / 40)$, speech $(65 / 70)$ and reading $(39 / 40)$ were all within normal limits. However, his ability for writing $(26 / 35)$ was impaired. Further analysis showed that the impairment was restricted 


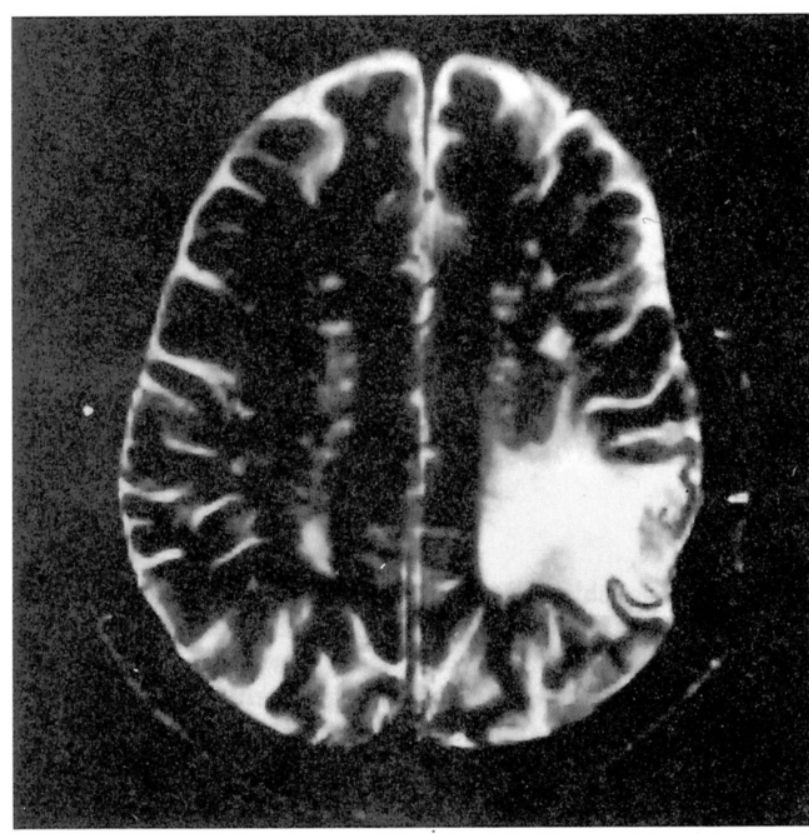

FIG. 1. $A_{2} T_{2}$-weighted magnetic resonance image. Imaging was carried out in a 0.5 Tesla superconducting system (Shimazu, Kyoto) using the spin-echo method. TR/TE = $2500 / 90 \mathrm{~ms}$. A $\mathrm{T}_{2}$ high intensity lesion is visible in the right marginal gyrus and adjacent subcortex

to Kana writing with preserved Kanji writing. There was no limb-kinetic, ideomotor or ideational apraxia. Copying of figures on the Benton Visual Retention Test (Benton, 1974) was perfect. Serial seven and copying of a cube were performed well. He had a full score on the Western Aphasia Battery praxis subtest (Kertez, 1980). The parietal lobe functions including

TABLE I. Results of neuropsychological examination

\begin{tabular}{lc}
\hline MMSE & \\
Total & $29 / 30$ \\
Orientation & $10 / 10$ \\
Registration & $3 / 3$ \\
Recall & $3 / 3$ \\
Language & $7 / 8$ \\
Attention & $5 / 5$ \\
Praxis & $1 / 1$ \\
Benton Visual Retention Test & \\
Trial A & $9 / 10$ \\
Trial C & $10 / 10$ \\
Western Aphasia Battery praxis subtest & $60 / 60$ \\
SLTA & \\
Verbal comprehension & $35 / 40(88 \%)$ \\
Speech & $65 / 70(93 \%)$ \\
Reading & $39 / 40(98 \%)$ \\
Writing & $26 / 35(74 \%)$ \\
\hline
\end{tabular}

122 Behavioural Neurology . Vol 8.1995 right-left orientation, two point discrimination, skin graphestesia, point localization, finger naming, optokinetic nystagmus, visually guided reaching, stereognosia and spatial orientation were intact. Double simultaneous stimulations including auditory, tactile guided reaching, spatial orientation and stereognosis were correctly perceived on both sides.

He made many Kana writing errors in spontaneous writing as well as on dictation, but Kanji writing was intact. Kana writing errors were characterized by substitution with another letter, but the substituted letter form was correct. Substituted letters were not related either phonetically or visually. Substitution did not occur in a particular location. Kana writing errors were found with both hands. After writing to dictation, he was often surprised at his errors but he could not correct them. Copying of Kana letters was well preserved.

To evaluate his ability to transcribe dictated words into Kanji and Kana, the following test was carried out (Tanaka et al., 1987). Fifty words with from one to five syllables were orally presented as stimuli. The number of target Kana letters corresponded to the number of syllables, while the number of target Kanji was one letter for one to three syllables, two letters for four syllables, and two or three letters for five syllables. First, the patient was asked to transcribe the dictated words into Kanji, then into Kana with the right hand. To test the effect of verbal immediate memory, he was asked to spell the dictated words aloud. In this test, his memory for the target words was normal. Even after he had written a dysgraphic sequence, he could always spell the syllable aloud correctly. Accordingly, his writing errors did not seem to be caused by an impairment of immediate memory. While Kanji writing was perfect, he made Kana writing errors if syllables of the stimulus words exceeded three. Kana errors consisted of substitution with another letter such as shinbun (newspaper) $\rightarrow$ shitsubun as shown in Fig. 2. The number of produced syllables was close to the number of syllables of the presented word. We also orally presented non-words having from one to five syllables as stimuli. He also made Kana writing errors if syllables of the stimulus words exceeded three. These errors consisted of substitution. In order to prove that he has a Kana agraphia rather than an agraphia for Kana and Kanji due to compromised graphemic buffer, we made him write longer Kanji words with one to five Kanji letters. He could always write these words correctly. His Kana agraphia remained unchanged until the last followup in August 1994.

Tables I and II show results of the neurophyschological examination and writing tests. 


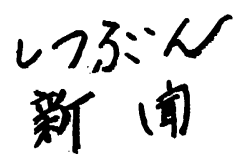

' SHI - TSU - BU - N '

' $\mathbf{S H I}-\mathbf{N}-\mathbf{B U} \cdot \mathbf{N}$ ' ( newspaper )

' $\mathrm{SE}-\mathbf{N}-\mathbf{P O}-\mathbf{U}-\mathbf{K I}{ }^{\prime}$

せNぱうシ

' SE - N - PU - U - KI ' ( electric fan )

FIG. 2. Examples of the patient's dictation of a four syllable and a five syllable word. All Kanji words shown in this figure were correct. The results of Kana writing are as follows. 'SHI-TSU-BU-N' is incorrect; it should be 'SHI-N-BU-N' (newspaper); 'SE-N-PO-U-KI' is incorrect; it should be 'SE-N-PU-U-KI' (electric fan). Kana errors were characterized by substitutions with another letter, but the letter forms and letter numbers were correct.

TABLE II. Results of writing tests

\begin{tabular}{lrrrrrr}
\hline & \multicolumn{7}{c}{ No. of syllables } \\
\cline { 2 - 6 } & 1 & 2 & 3 & 4 & 5 & Total \\
\hline Dictation & 10 & 10 & 7 & 6 & 6 & $39(78 \%)$ \\
$\quad$ Kana writing (10 words) & 10 & 9 & 6 & 6 & 6 & $37(74 \%)$ \\
$\quad$ Kana writing (10 non- & 10 & 10 & 10 & 10 & 10 & $50(100 \%)$ \\
$\quad$ words) & & & & & 10 & $50(100 \%)$ \\
$\quad$ Kanji writing (10 words) & 10 & 10 & 10 & 10 & 10 & $50(100 \%)$ \\
Copy & 10 & 10 & 10 & 10 & 10 & \\
$\quad$ Kana writing (10 words) & & & & & & \\
Kanji writing (10 words) & &
\end{tabular}

\section{DISCUSSION}

The patient presented here showed selective Kana agraphia with other linguistic skills preserved, including Kanji writing. The main features of Kana agraphia in our patient were: (1) Kana writing was selectively impaired compared to Kanji; (2) the errors in Kana writing consisted of substitutions but the number of Kana letters produced was a good approximation to the number of syllables of the target word; (3) the letter forms were well preserved; and (4) the responsible lesion was in the non-dominant superior temporal gyrus, marginal gyrus and adjacent subcortex. Although there are a few reports describing patients with Kana agraphia, the responsible lesions have varied widely, including the left frontal (Sato et al., 1983), the left parietal (Kimura et al., 1986; Tanaka et al., 1987) and the left temporal region (Tanaka et al., 1987), but they were all on the dominant side.

Although the precise processing system for writing remains uncertain, a few models for writing have been proposed (Roeltgen, 1993). In countries where alphabets are used, the current model for production of a letter string is based on the hypothesis that its abstract representation is computed and stored in a temporary graphemic or orthographic buffer, from which the abstract form is converted to a physical letter code. In the case of Kana writing, with a notable difference in the writing system, we may use an analogous orthographic buffer (Roeltgen, 1993). The schematic model for language activity, part of which has been supported by investigations using positron emission tomography (Petersen et al., 1988) and magnetic encephalography (Salmelin et al., 1994), proposes that the neuronal network for writing is activated from the graphemic buffer via the graphemic area (the dominant parietal lobe) and the graphic output programming area (the dominant middle frontal lobe, Exner's area?) to the motor programming area (the motor area). Therefore, any damage to this neuronal network can produce 
agraphia, and the anatomic variability among the responsible lesions in patients with Kana agraphia can be explained by the presence of this wide neuronal network.

The most unique feature of Kana agraphia in our patient was that he had a single lesion in the nondominant cerebral hemisphere. It has long been conjectured that non-dominant hemispheric lesions could affect Kanji reading and writing without involving Kana (Joanette et al., 1982), although there is little evidence for this (Iwata, 1986; Sakura et al., 1992). Our case demonstrated the opposite, and provided important information as to the lateralization of the language function (Geshwind and Levitsky, 1968; Sakura et al., 1992). Whether a lesion in the nondominant right hemisphere, corresponding to the language area in the normal dominant hemisphere, can cause a similar language disorder has not been studied. The lesion in our case included the homologous Wernicke's area (the posterior one-third or one-half of the superior temporal gyrus), which in the left hemisphere would cause Wernicke's aphasia. However, the patient's only language dysfunction was Kana agraphia without impairment in comprehension or speech. The current theory supports the notion that the degree of right hemisphere lateralization of the language function in crossed aphasia in dextral patients, namely almost complete lateralization to the right hemisphere, may be comparable to that of left hemispheric lateralization in ordinary dextral people (Boller, 1973; Trojanowski et al., 1980; Sweet et al., 1984). However, our case did not fit this theory well. A sudden onset of Kana agraphia without other language dysfunctions in our patient suggests that the non-dominant superior temporal gyrus, marginal gyrus and adjacent subcortex exclusively conducted the neural activities for Kana writing. This case would contribute to dissociating Kana agraphia from the phonological system and confirm the sight vocabulary writing process. Thus, we believe that in some dextral people, the language function may be partially lateralized to the right hemisphere.

\section{REFERENCES}

Benton AL (1974) The revised Visual Retention Test, 4th edn. Psychological Corporation, New York.
Boller F (1973) Destruction of Wernicke's area without language disturbance: a fresh look at crossed aphasia. Neuropsychologia, 11, 243-246.

Geschwind N and Levitsky W (1968) Human brain: left-right asymmetries in temporal speech region. Science, 161, 186 187.

Iwata M (1986) Neural mechanism of reading and writing in the Japanese language. Functional Neurology, 1, 4352.

Joanette Y, Puel M, Nespoulous J-L, Rascol A and Lecours AR (1982) Aphasie croisee chez les droiters: I. Revue de la litterature. Revue Neurologique (Paris), 138, 575586.

Kertesz A (1980) Western Aphasia Battery. University of Western Ontario Press, London, Ontario.

Kimura B, Matsuda K, Kuroiwa Y and Tohgi H (1986) Pure agraphia in the left parietal subcortical infarction. Neurological Medicine, 24, 484-488.

Leischner A (1969) Agraphias. In: Clinical Naurology, Vol. 4 (Eds PJ Vinken and GW Bruyn), pp. 141-180. NorthHolland, Amsterdam.

Oldfield RC (1971) The assessment and analysis of handedness: the Edinburgh inventory. Neuropsychologia, 9, 97113.

Petersen SE, Fox PT, Posner MI et al. (1988) Positron emission tomographic studies of the cortical anatomy of single-word processing. Nature, 331, 585-589.

Roeltgen DP (1993) Agraphia. In: Clinical Neurology, 2nd edn (Eds KM Heilman and E Valenstein), pp. 63-89. Oxford University Press, Oxford.

Sakurai Y, Kurisaki H, Takeda K et al. (1992) Japanese crossed Wernicke's aphasia. Neurology, 42, 144 148.

Salmelin R, Hari R, Lounasmaa OV and Sams M (1994) Dynamics of brain activation during picture naming. Nature, 368, 463-465.

Sato M, Yasui N, Suzuki A et al. (1983) Agraphia from the frontal lesion: a case of Moyamoya disease. Brain and Nerve, 35, 1145-1151.

Sweet EWS, Panis W and Levine DN (1984) Crossed Wernicke's aphasia. Neurology, 34, 475-479.

Takeda K (1977) Standard language test of aphasia (SLTA). Detailed description of construction of aphasia test in Japanese. Advances in Neurological Sciences (Tokyo), 21, 1001-1015 (in Japanese).

Tanaka Y, Yamadori A, Mori E et al. (1987) Selective Kana agraphia: a case report. Cortex, 23, 679684.

Trojanowski JQ, Green RC and Levine DN (1980) Crossed aphasia in a dextral: a clinicopathological study. Neurology, 30, 709-713.

(Received 6 March 1995; accepted as revised 10 July 1995) 


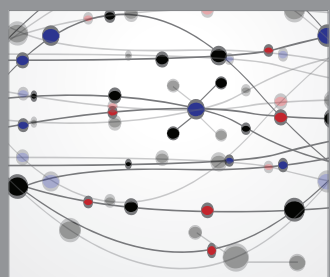

The Scientific World Journal
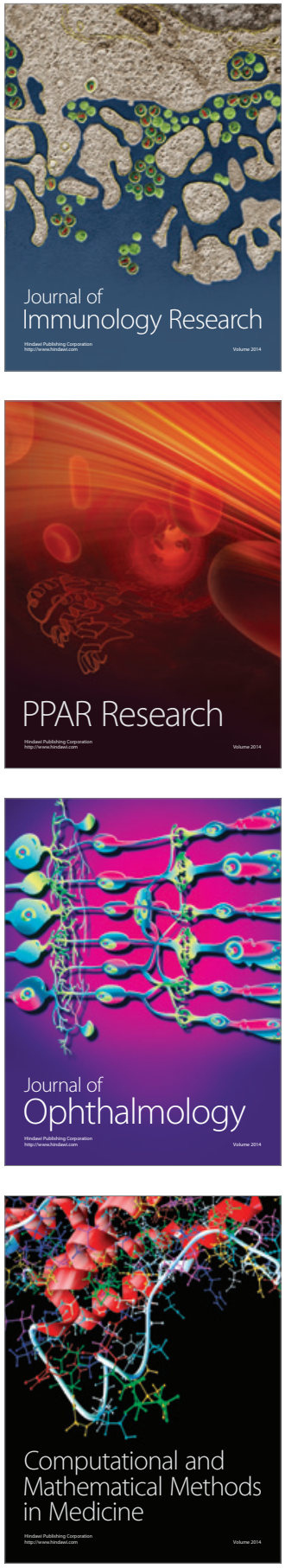

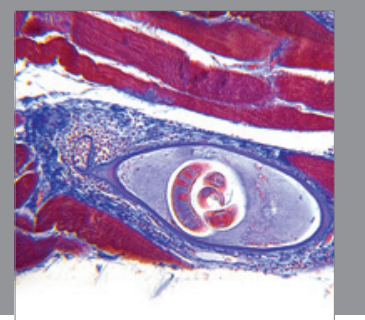

Gastroenterology

Research and Practice
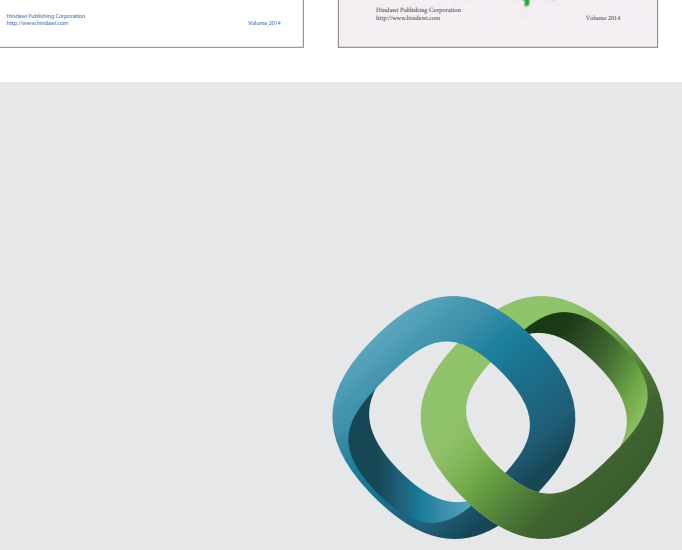

\section{Hindawi}

Submit your manuscripts at

http://www.hindawi.com
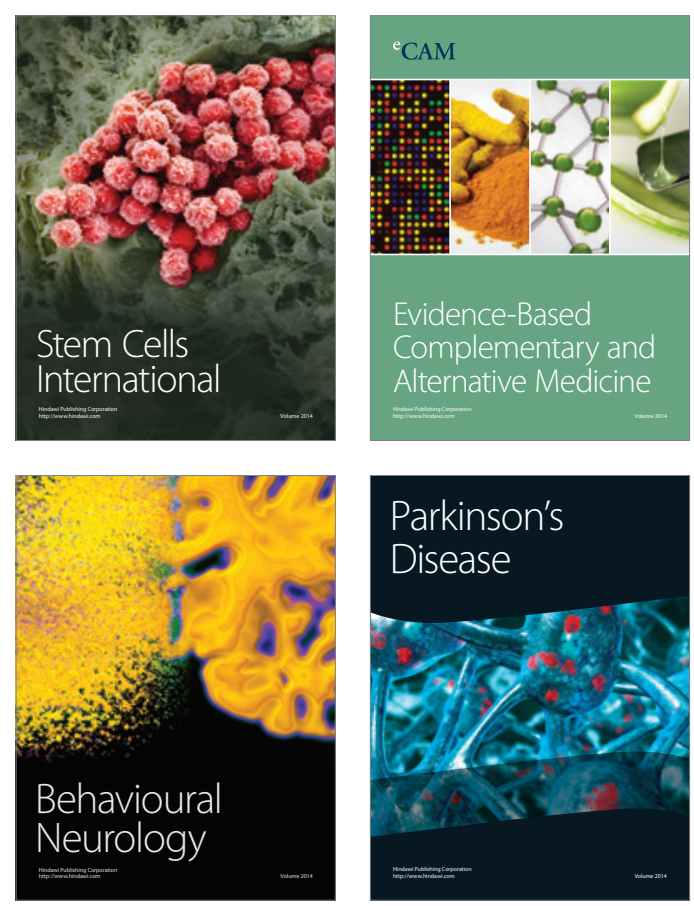

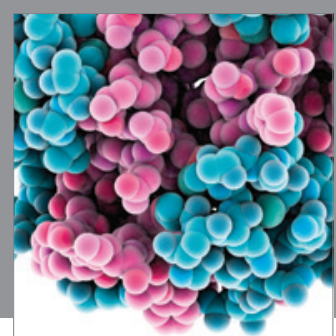

Journal of
Diabetes Research

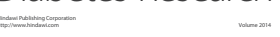

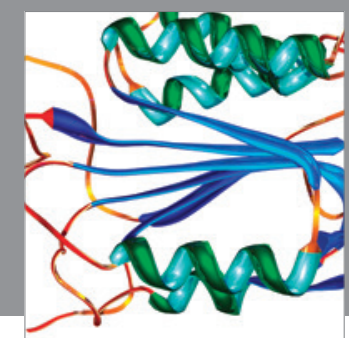

Disease Markers
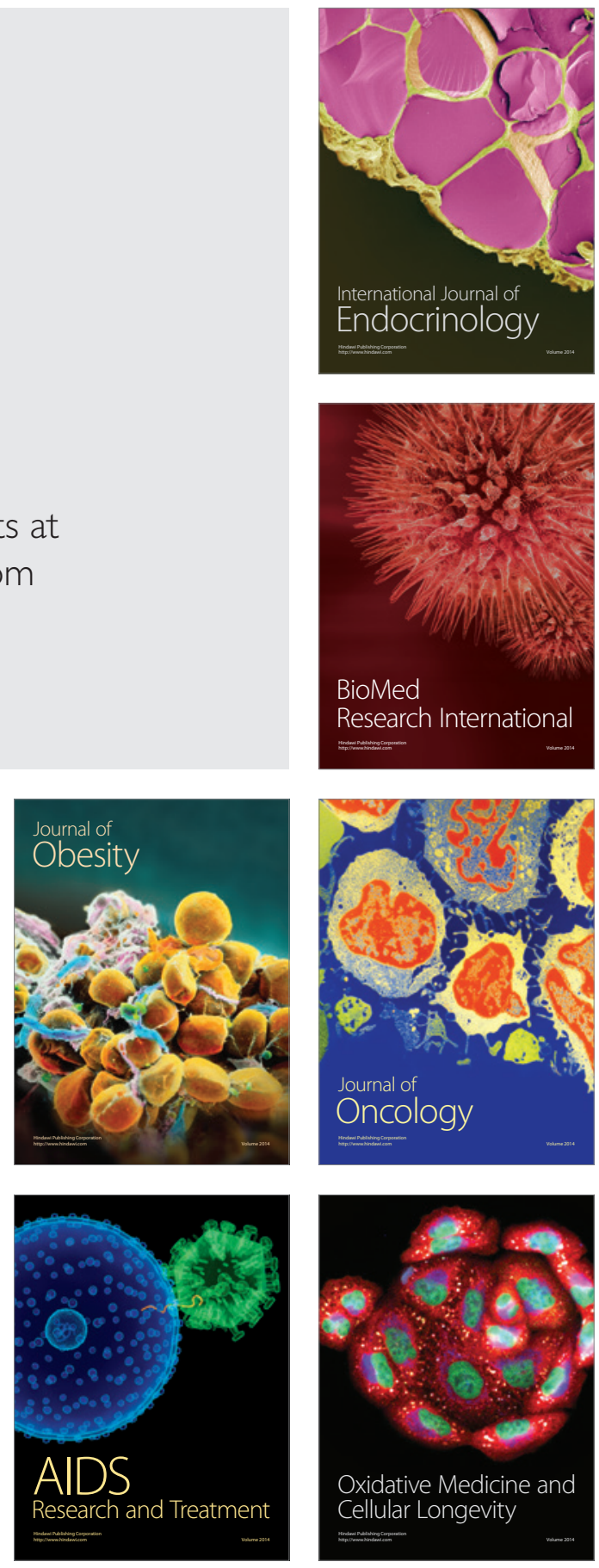